\title{
Usefulness and limitations of circumferential fibre shortening velocity in evaluating segmental disorders of left ventricular contraction
}

\author{
Pedro R. Hernandez-Lattuf, ${ }^{1}$ Miguel A. Quinones, ${ }^{2}$ and William H. Gaasch ${ }^{3}$ \\ From the Department of Medicine, Baylor College of Medicine, and Ben Taub General Hospital, Houston, \\ Texas, U.S.A.
}

In order to study the possibility of using circumferential fibre shortening velocity $\left(V_{\mathrm{CF}}\right)$ to assess regional left ventricular performance, 21 left ventricular angiograms (single-plane cine) from 19 patients were examined. In 8 patients with normal left ventricle, measurements of instantaneous and mean $V_{\mathrm{CF}}$ in 4 equidistant chords revealed uniform velocities at all chords. In 7 patients with coronary artery disease mean and max $V_{\mathrm{CF}}$ were depressed in the areas involved by asynergy; however, when only one wall was affected, velocity measurements of the hemichords provided a better definition of regional performance. $V_{\mathrm{CF}}$ at the base (chords $A$ and $B$ ) was normal in 2 out of 3 patients with apical asynergy, and augmented in one. Angiotensin produced a reduction in the mean velocity of the anterior wall in a patient with inferior dyskinesis-akinesis; in contrast, nitroglycerin was associated with augmented velocity of the non-akinetic segment in a second patient with inferior akinesis and anteroapical hypokinesis.

In contrast to localized asynergy, a diffuse reduction in $V_{\mathrm{CF}}$ was observed in a patient with cardiomyopathy. $V_{\mathrm{CF}}$ at the base was reduced in a patient with mitral stenosis and in another with mitral valve prolapse, indicating the presence of a localized basal abnormality of left ventricular contraction. The time course of $V_{\mathrm{CF}}$ in the patient with mitral prolapse showed an early peak before aortic valve opening, corresponding to a reduction in left ventricular volume $(\Delta V)$ of 22 per cent (in contrast to 3 per cent reduction in the normal left ventricle). Fibre shortening before aortic valve opening was also present in chronic mitral regurgitation $(\Delta V=15 \%)$.

Segmental analysis of normalized velocities provides a quantitative approach to the evaluation of regional left ventricular performance. The sensitivity of $V_{\mathrm{CF}}$ to acute changes in loading, however, may limit in some instances the usefulness of this index.

The search for a sensitive and simple method to measure the inotropic state of left ventricular myocardium has been a continuing and important one. Determination of instantaneous tensionvelocity relations throughout ejection provides a sensitive means of comparing the level of the ventricular contractile state among patients (Gault, Ross, and Braunwald, I968). However, such analysis requires frame by frame measurements of left ventricular dimensions, accurate estimations of

Received 22 April 1974.

'Fellow in Cardiology, St. Luke's Episcopal Hospital and the Texas Heart Institute.

2 Supported by a research fellowship award of the American Heart Association and its Texas Affiliate.

${ }^{3}$ Present address: New England Medical Center Hospitals, I7I Harrison Avenue, Boston, Mass. 0211 I, U.S.A. changes in ventricular wall thickness, and high fidelity left ventricular pressure recordings. In contrast, it has been shown that the mean velocity of circumferential fibre shortening $\left(\mathrm{V}_{\mathrm{CF}}\right)$ provides a relatively simple and satisfactory measurement of left ventricular performance, even when valvular and myocardial defects coexist (Karliner et al., I97Ib). Quantitative comparison of the left ventricular performance among patients is also possible since velocity is divided by end-diastolic circumference and expressed per unit of circumferential length. The applicability of this method has been based on the assumption that mean $\mathrm{V}_{\mathrm{CF}}$ at the minor equator reflects the inotropic state of the entire ventricle, an assumption precluded by the presence of segmental myocardial disease. The purpose of the present study is to examine the usefulness and 
limitations of segmental measurements of $\mathrm{V}_{\mathrm{CF}}$ in the evaluation of localized disorders of left ventricular contractility.

\section{Methods}

Left ventricular cineangiograms obtained from I9 patients, 21 to 59 years of age, were analysed. One group (8 patients) had normal haemodynamics at rest, normal synergy of left ventricular contraction, and normal coronary arteriograms. A second group (II patients) consisted of 7 cases of coronary artery disease with abnormal left ventricular performance and regional disorders of wall motion, 3 patients with valvular lesions (mitral stenosis, mitral regurgitation, and mitral prolapse), and one patient with congestive cardiomyopathy. The patients included in this report were selected on the basis of representing a portion of a disease spectrum; they were not necessarily considered representative or average cases. High quality left ventricular cineangiograms were required (adequate left ventricular opacification without premature contractions). All patients were in normal sinus rhythm.

Diagnostic right and left heart catheterization was performed in the post-absorptive state. Left ventricular angiograms (single-plane cine, right anterior oblique) were obtained, with injection of 45 to $55 \mathrm{ml}$ contrast material (Renografin 76) through a multiple side-holes catheter at a film speed of 60 frames/second. A second left ventricular angiogram was performed in 2 patients: in $I$ of them the angiogram was done 2 minutes after the administration of nitroglycerin ( $0.8 \mathrm{mg}$ sublingual); in the other patient, the left ventricular angiogram was performed during an infusion of angiotensin $(2 \mu \mathrm{g} / \mathrm{ml}$ in $5 \% \mathrm{D} / \mathrm{W}$ ) at a rate sufficient to produce a distinct pressor response. The ventriculograms were inspected frame by frame; end-diastole was defined as the earliest frame to show maximum endocardial outward excursion (maximum volume). Aortic valve opening, identified by observation of the valve leaflets motion, occurred $4 \pm$ I frames $(67 \pm 17 \mathrm{msec})$ after end-diastole; therefore, the fifth frame following end-diastole was selected as the onset of left ventricular ejection in all cases. End-systole was defined as the frame showing maximal endocardial inward motion (minimum volume). The left ventricular ejection time (LVET) was determined by the number of frames from the onset of ejection to end-systole. In the patient with mitral regurgitation, and in the mitral valve prolapse, the period from end-diastole to aortic valve opening was included in the calculation of the ejection time. The left ventricular cavity was drawn at enddiastole, and every fourth frame throughout systole. In each drawing a long axis was constructed from the ventricular apex to the angle formed by the profile of the mitral valve and the posterior sinus of the aortic valve. Five equidistant chords joining the anterior endocardial surface to the inferior surface were drawn perpendicular to the long axis. The chords were identified as $\mathrm{A}$ to $\mathrm{E}$ from the base to the apex. Analysis of the velocity of chord $\mathrm{E}$ was not performed because of the apparent absence of this chord at end-systole (apical cavity obliteration) in several normal ventricles. Chords A to D can be seen in the angiogram shown in Fig. 5.
The mean circumferential fibre shortening rate (mean $\mathrm{V}_{\mathrm{CF}}$ in circumferences/sec) for each chord was calculated as

$$
\text { mean } \mathrm{V}_{\mathrm{CF}}=(\mathrm{Dd}-\mathrm{Ds}) / \mathrm{Dd} \times \text { LVET }
$$

where $\mathrm{Dd}$ and $\mathrm{Ds}$ represent the chord or diameter at enddiastole and at end-systole, respectively. In 4 patients, the mean shortening velocity of the anterior and posterior hemichords (radii) was also calculated by substituting radius for diameter in the above formula. 'Instantaneous' circumferential fibre shortening velocity was determined every $67 \mathrm{msec}$ (every 4 frames) as

$$
\mathrm{V}_{\mathrm{CF}}=\left(\mathrm{D}_{1}-\mathrm{D}_{2}\right) / \mathrm{D}_{1} \times 0.067
$$

where $D_{1}=$ initial chord length and $D_{2}=$ final chord length. Measurements were started at end-diastole and carried on every fourth frame throughout systole. The systolic ejection fraction was determined using the method of Greene et al. (1967). In selected cases (mitral regurgitation and mitral prolapse) left ventricular volume was determined at end-diastole, at the time of aortic valve opening, and at end-systole. Dimensions were corrected for magnification and distortion by means of a reference ( $\mathrm{I} \mathrm{cm}$ squares) grid. Total stroke volume was taken as the difference between end-diastolic and endsystolic volume; regurgitant volume was calculated as the difference between the total stroke volume and the forward stroke volume (determined according to the Fick principle for oxygen).

\section{Results}

The data are presented in the Table and in Fig. I to 6 .

\section{Normal pattern of left ventricular contraction}

The normal pattern of contraction was characterized by a uniform inward motion of the ventricular endocardium during systole. As shown in Fig. I, mean $V_{C F}$ was similar for each chord. Likewise, 'instantaneous' $V_{\mathrm{CF}}$, derived from every fourth cine frame, was similar in each of the four chords (Fig. 2). Peak $V_{C F}$ occurred between $I 33$ and $200 \mathrm{msec}$ after end-diastole. $V_{C F}$ before aortic valve opening averaged $0.2 \mathrm{circ} / \mathrm{sec}$, corresponding to a change in volume of 3 per cent.

\section{Abnormal pattern of left ventricular contrac- tion}

Analysis of mean and 'instantaneous' $V_{C F}$ for Cases 9, 10 , and 13 is shown in Fig. $I$ and 2. A reduction in both mean and peak $V_{C F}$ was found in the chords adjacent to areas showing localized disorders of wall motion. Both mean and peak $\mathrm{V}_{\mathrm{CF}}$ were well preserved in the non-involved areas of the patients with apical disease (Cases 9, IO, and II); 2 of these 3 patients had normal ejection fractions. In Case 9 the velocity of fibre shortening in chord $B$ appeared to be greater than that observed in any of the normal hearts (Fig. I and 2). As is shown in Fig. 3, mean 
TABLE

\begin{tabular}{|c|c|c|c|c|c|c|c|c|c|c|c|c|}
\hline $\begin{array}{l}\text { Case } \\
\text { no. }\end{array}$ & Age/sex & $\begin{array}{l}B S A \\
\left(m^{2}\right)\end{array}$ & $\begin{array}{l}V_{\mathrm{CF}}(c \\
\text { Chord } \\
\text { Max }\end{array}$ & $\begin{array}{l}\text { circ/sec) } \\
A \\
\text { Mean }\end{array}$ & $\begin{array}{l}\text { Chord } \\
\text { Max }\end{array}$ & Bean & $\begin{array}{l}\text { Chord } \\
\text { Max }\end{array}$ & $\begin{array}{l}C \\
\text { Mean }\end{array}$ & $\begin{array}{l}\text { Chord } \\
\text { Max }\end{array}$ & $\begin{array}{l}D \\
\text { Mean }\end{array}$ & Clinical diagnoses & $S E F$ \\
\hline I & $46 / M$ & $\mathrm{I} \cdot 75$ & 3.49 & I.59 & $3 \cdot 19$ & I.99 & $3 \cdot 49$ & $I \cdot 96$ & $4 \cdot 12$ & $2 \cdot 04$ & $\begin{array}{l}\text { Left anterior descending } \\
\text { artery - right ventricular } \\
\text { fistula }\end{array}$ & $65 \%$ \\
\hline 2 & $40 / F$ & $I \cdot 64$ & 2.53 & $I \cdot 18$ & $3 \cdot 35$ & $\mathrm{I} \cdot 55$ & $2 \cdot 45$ & $\mathrm{I} \cdot 39$ & 3.53 & $\mathbf{1} \cdot 58$ & $\begin{array}{l}\text { Chest pain, normal } \\
\text { coronary artery }\end{array}$ & $73 \%$ \\
\hline 3 & $59 / M$ & $2 \cdot 25$ & 3.50 & $2 \cdot 42$ & $3 \cdot 34$ & $2 \cdot 50$ & $3 \cdot 76$ & $2 \cdot 63$ & $2 \cdot 63$ & $2 \cdot 12$ & $\begin{array}{l}\text { Chest pain, normal } \\
\text { coronary artery }\end{array}$ & $85 \%$ \\
\hline 4 & $22 / M$ & $2 \cdot 26$ & I·39 & $0 \cdot 78$ & $2 \cdot 53$ & $I \cdot 10$ & $2 \cdot 61$ & $\mathrm{I} \cdot 20$ & $2 \cdot 89$ & $\mathrm{I} \cdot 04$ & Functional murmur & $60 \%$ \\
\hline 5 & $26 / F$ & $\mathrm{I} \cdot 83$ & 3.53 & $I \cdot 46$ & 3.55 & $1 \cdot 50$ & $3 \cdot 20$ & $I \cdot 46$ & $3 \cdot 35$ & $1 \cdot 50$ & $\begin{array}{l}\text { Chest pain, normal } \\
\text { coronary artery }\end{array}$ & $82 \%$ \\
\hline 6 & $2 I / M$ & $\mathrm{I} \cdot 84$ & $2 \cdot 42$ & $I \cdot I I$ & $2 \cdot 33$ & $I \cdot 30$ & $2 \cdot 37$ & $\mathbf{I} \cdot \mathbf{2 2}$ & $2 \cdot 27$ & $\mathbf{I} \cdot \mathbf{I} \mathbf{I}$ & Functional murmur & $66 \%$ \\
\hline 7 & $53 / \mathrm{M}$ & $2 \cdot 13$ & & & $3 \cdot 19$ & $1 \cdot 50$ & $2 \cdot 79$ & $1 \cdot 47$ & 2.46 & $I \cdot 4 I$ & $\begin{array}{l}\text { Chest pain, normal } \\
\text { coronary artery }\end{array}$ & $60 \%$ \\
\hline 8 & $43 / M$ & $1 \cdot 67$ & $2 \cdot 32$ & $I \cdot 36$ & 3.53 & $I \cdot 7 I$ & 3.67 & $1 \cdot 73$ & 3.55 & $\mathrm{I} \cdot 86$ & $\begin{array}{l}\text { Chest pain, normal } \\
\text { coronary artery }\end{array}$ & $64 \%$ \\
\hline \multirow{3}{*}{\multicolumn{2}{|c|}{$\begin{array}{l}\text { Mean } \\
\text { SD } \\
\text { SEM }\end{array}$}} & & $2 \cdot 74$ & $I \cdot 4 I$ & $3 \cdot 13$ & I. 64 & 3.04 & $I \cdot 63$ & $3 \cdot 10$ & $\mathrm{I} \cdot 58$ & & \\
\hline & & & 0.54 & 0.52 & 0.31 & 0.42 & 0.38 & 0.48 & 0.43 & 0.27 & & \\
\hline & & & 0.21 & 0.20 & 0.11 & 0.15 & 0.20 & 0.17 & 0.23 & 0.14 & & \\
\hline 9 & $50 / F$ & $\mathrm{I} \cdot 80$ & $2 \cdot 49$ & $I \cdot 4 I$ & $5 \cdot 10$ & $2 \cdot 06$ & $2 \cdot 57$ & $I \cdot 50$ & $2 \cdot 10$ & 0.92 & $\begin{array}{l}\text { Coronary artery disease, } \\
\text { apical hypokinesis }\end{array}$ & $67 \%$ \\
\hline I0 & $59 / F$ & $I \cdot 60$ & 2.58 & $I \cdot 46$ & $2 \cdot 46$ & $I \cdot 2 I$ & 0.76 & 0.51 & 0.32 & 0.14 & $\begin{array}{l}\text { Coronary artery disease, } \\
\text { apical akinesis }\end{array}$ & $46 \%$ \\
\hline I I & $42 / F$ & I.97 & $2 \cdot 45$ & $I \cdot 66$ & $2 \cdot 14$ & $I \cdot 4 I$ & I.09 & $1 \cdot 08$ & 0.88 & 0.87 & $\begin{array}{l}\text { Coronary artery disease, } \\
\text { apical akinesis }\end{array}$ & $63 \%$ \\
\hline 12 & $36 / \mathrm{M}$ & $I \cdot 74$ & $I \cdot 30$ & 0.91 & $I \cdot 39$ & 0.86 & $I \cdot 15$ & 0.96 & $2 \cdot 00$ & 0.84 & $\begin{array}{l}\text { Coronary artery disease, } \\
\text { anterior-apical hypokinesis }\end{array}$ & $47 \%$ \\
\hline I3 & $49 / M$ & $\mathrm{I} \cdot 88$ & $I \cdot 32$ & 0.97 & $I \cdot I 9$ & 0.68 & $I \cdot 50$ & 0.39 & 0.64 & 0.19 & $\begin{array}{l}\text { Coronary artery disease, } \\
\text { anterior-apical akinesis }\end{array}$ & $34 \%$ \\
\hline 14 & $48 / M$ & 2.05 & $\mathrm{r} \cdot 45$ & 0.69 & $\mathrm{I} \cdot 57$ & 0.78 & $2 \cdot 75$ & 0.87 & $2 \cdot 74$ & $I \cdot 19$ & $\begin{array}{l}\text { Coronary artery disease, } \\
\text { inferior dyskenesis- } \\
\text { akinesis }\end{array}$ & $52 \%$ \\
\hline 15 & $48 / M$ & 1.95 & 0.88 & 0.67 & 0.93 & 0.74 & 0.87 & 0.70 & 0.98 & 0.62 & $\begin{array}{l}\text { Coronary artery disease, } \\
\text { inferior akinesis }+ \\
\text { anterior-apical hypokinesis }\end{array}$ & $39 \%$ \\
\hline 16 & $56 / F$ & $\mathrm{I} \cdot 85$ & 0.40 & 0.20 & 0.60 & 0.21 & 0.38 & 0.22 & 0.18 & 0.24 & Congestive cardiomyopathy & $25 \%$ \\
\hline 17 & $22 / M$ & $I \cdot 80$ & I.87 & $\mathrm{I} \cdot 02$ & 2.09 & 0.89 & $3 \cdot 24$ & $2 \cdot 10$ & $3 \cdot 29$ & $I \cdot 90$ & Mitral stenosis & $72 \%$ \\
\hline I8 & 30/M & $2 \cdot 01$ & 0.80 & 0.34 & $\mathrm{I} \cdot 84$ & $r \cdot 60$ & $\mathbf{I} \cdot 90$ & $I \cdot 23$ & $I \cdot 78$ & $\mathbf{I} \cdot 09$ & Mitral valve prolapse & $63 \%$ \\
\hline 19 & $34 / \mathrm{M}$ & $\mathrm{I} \cdot 54$ & $2 \cdot 22$ & $\mathbf{I} \cdot \mathbf{2 7}$ & $2 \cdot 27$ & $\mathrm{I} \cdot 34$ & $2 \cdot 29$ & $I \cdot 3 I$ & $2 \cdot 82$ & $I \cdot 4 I$ & Mitral regurgitation & $71 \%$ \\
\hline
\end{tabular}

* Pulmonary to systemic flow ratio $<I \cdot I: I$.

Abbreviations: $V_{C F}=$ circumferential fibre shortening rate; $B S A=$ body surface area; Max $=$ maximum; $S D=s t a n d a r d ~ d e v i a-$ tion; $\mathrm{SEM}=$ standard error of the mean. $\mathrm{SEF}=$ systolic ejection fraction.

$\mathrm{V}_{\mathrm{CF}}$ in all 4 chords was reduced in Case $\mathrm{I} 4$ (inferior dyskinesis-akinesis) while the mean normalized velocities of the anterior hemichords (radii) were normal. Likewise in Case I2 (anteroapical hypokinesis), mean $\mathrm{V}_{\mathrm{CF}}$ was reduced in all chords while inferior wall motion was preserved. There was good agreement between circumferential and radial velocities in the normal (Fig. 3). The patient with anteroapical akinesis (Case 13) had generalized reduction in the extent $(\mathrm{SEF}=34 \%$ ) and velocities of wall motion (Fig. I and 2). This patient qualitatively resembles the patient with congestive cardiomyopathy (Case 16).
In the patient with mitral stenosis (Case I7), both mean and 'instantaneous' $V_{C F}$ were reduced at the base (chords A and B) and normal towards the apex (chords $\mathrm{C}$ and $\mathrm{D}$ ). The systolic ejection fraction was normal $(72 \%)$ (see Fig. I and 4).

A striking reduction in mean and 'instantaneous' $V_{C F}$ was observed at chord $A$ in the patient with mitral valve prolapse (Case 18 ). Though mean $V_{C F}$ was preserved in the remaining chords, peak $V_{C F}$ was slightly reduced (Fig. I and 4). Prolapse of the posterior leaflet of the mitral valve began immediately after end-diastole and reached maximum shortly after aortic valve opening (Fig. 5); prolapse 

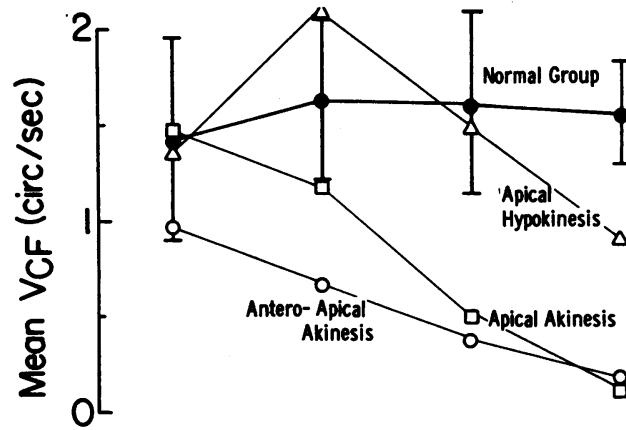

A

C
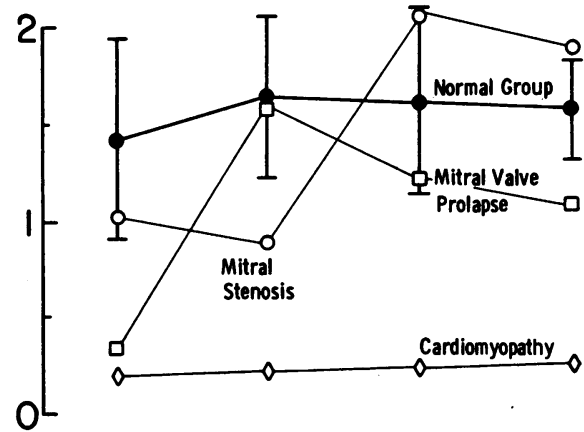

A

FI G. I Mean $V_{\mathrm{CF}}$ (average $\pm S D$ ) for chords $A$ to $D$ in the normal group and in several patients with asynergy are shown. In the normal left ventricle, $V_{\mathrm{CF}}$ is uniform in each of the four chords. Segmental abnormalities of wall motion are associated with reduced $V_{\mathrm{CF}}$ in the involved areas.
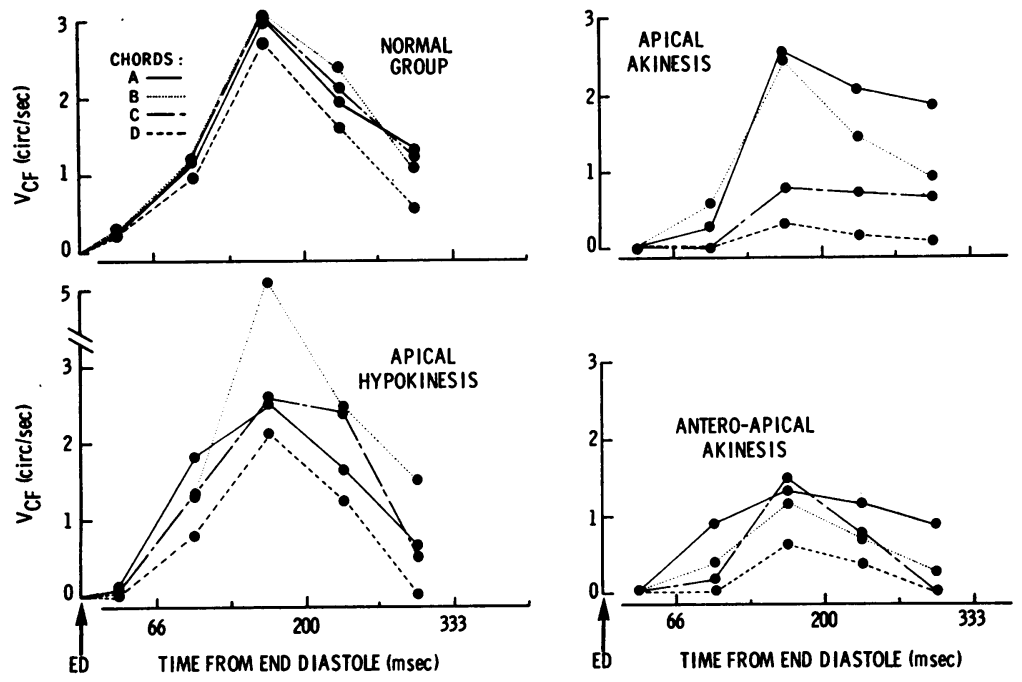

FIG. 2 The 'instantaneous' course of circumferential fibre shortening velocity for the normal group is shown in the panel on the upper left; three individual examples of coronary artery disease with asynergy are also shown. In the normal left ventricle the time course of $V_{\mathrm{CF}}$ is similar in each chord. Segmental reductions in $V_{\mathrm{CF}}$ are seen in the patients with asynergy. Note the high value for peak $V_{\mathrm{CF}}$ at the base (chord $B$ ) in the patient with apical hypokinesis.

was accompanied by significant fibre shortening (average $\mathrm{V}_{\mathrm{CF}}=\mathrm{I} \cdot 8 \mathrm{circ} / \mathrm{sec}$ ) in chords $\mathrm{B}, \mathrm{C}$, and $\mathrm{D}$ during the 'isovolumic' period (Fig. 4). In this patient the end-diastolic volume was $90 \mathrm{ml} / \mathrm{m}^{2}$, the volume remaining within the left ventricular cavity at the time of aortic valve opening was $70 \mathrm{ml} / \mathrm{m}^{2}$, total angiographic stroke volume was $56 \mathrm{ml} / \mathrm{m}^{2}$ and the total 'regurgitant' volume was $25 \mathrm{ml} / \mathrm{m}^{2}$. No regurgitation of dye into the left atrium was seen; the 'regurgitant volume' was, therefore, contained within the mitral valve apparatus.

Chronic rheumatic mitral regurgitation, likewise, was associated with volume reduction and significant fibre shortening before aortic valve opening. In this patient regurgitation of contrast into the left atrium began immediately after end-diastole and 

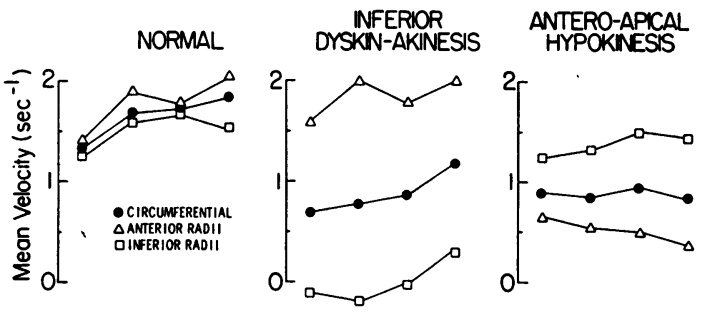

A $\quad$ B $\quad C \quad D$

A B C D

A $B \quad C \quad D$

FIG. 3 Mean circumferential fibre shortening velocity and the mean normalized velocities of the hemichords (radii) from a normal (panel on the left) and from two patients with asynergy are shown. In left ventricular asynergy, analysis of the hemichords provides better definition of regional performance than $V_{\mathrm{CF}}$. See text for details.

appeared to continue throughout systole. The end-diastolic volume was $136 \mathrm{ml} / \mathrm{m}^{2}$, the volume at the time of aortic valve opening was $116 \mathrm{ml} / \mathrm{m}^{2}$, the total stroke volume was $91 \mathrm{ml}$, and the regurgitant volume was $47 \mathrm{ml}$. In contrast to the localized basal reduction in $\mathrm{V}_{\mathrm{CF}}$ observed in the patient with mitral valve prolapse, this patient demonstrated uniform velocity of fibre shortening in all chords; the mean $V_{C F}$ fell within the normal range (Table), while peak $V_{C F}$ appeared slightly below normal (Fig. 4).
Fig. 6 shows the effect of alterations in loading conditions on mean $\mathrm{V}_{\mathrm{CF}}$, as well as on the mean velocities of the anterior and inferior radii, in 2 patients with coronary artery disease. Case I4 (inferior dyskinesis-akinesis) showed a pronounced reduction in the velocities of the anterior hemichords and a further increase in dyskinesis during an angiotensin infusion (increased afterload); ejection fraction fell from 52 to 35 per cent. In contrast, Case I5 (inferior akinesis with antero-apical hypokinesis) showed improvement in the velocities of the anteroapical hemichords and an increase in the ejection fraction ( $39 \%$ to $47 \%$ ) after administration of nitroglycerin; however, the inferior wall motion remained poor.

\section{Discussion}

Analysis of circumferential fibre shortening rate in several chords of the normal left ventricle has revealed similar mean and 'instantaneous' velocities in all chords. Within a given normal ventricle any intracavitary pressure will be associated with uniform levels of wall stress throughout the ventricle, so long as the ratio of radius to wall thickness remains constant (Sandler and Dodge, 1963). If all areas of the left ventricle are subjected to similar inotropic influences and to similar loading conditions, uniform shortening velocities are to be expected. The values for mean and $\max V_{C F}$ found in this study are in general agreement with those pre-
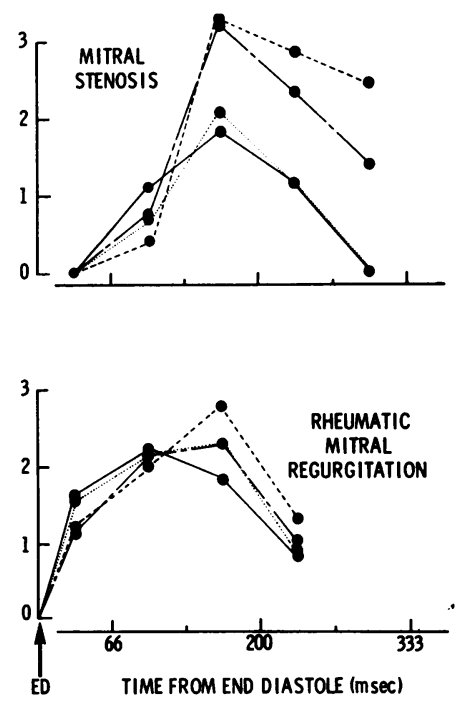

FIG. 4 The 'instantaneous' course of circumferential fibre shortening velocity for the normal group and for 3 patients with mitral valve disease are shown. Both mitral stenosis and mitral valve prolapse demonstrate a reduction in $V_{\mathrm{CF}}$ at the base. In both the prolapse and the rheumatic mitral regurgitation, significant fibre shortening occurred before aortic valve opening. 


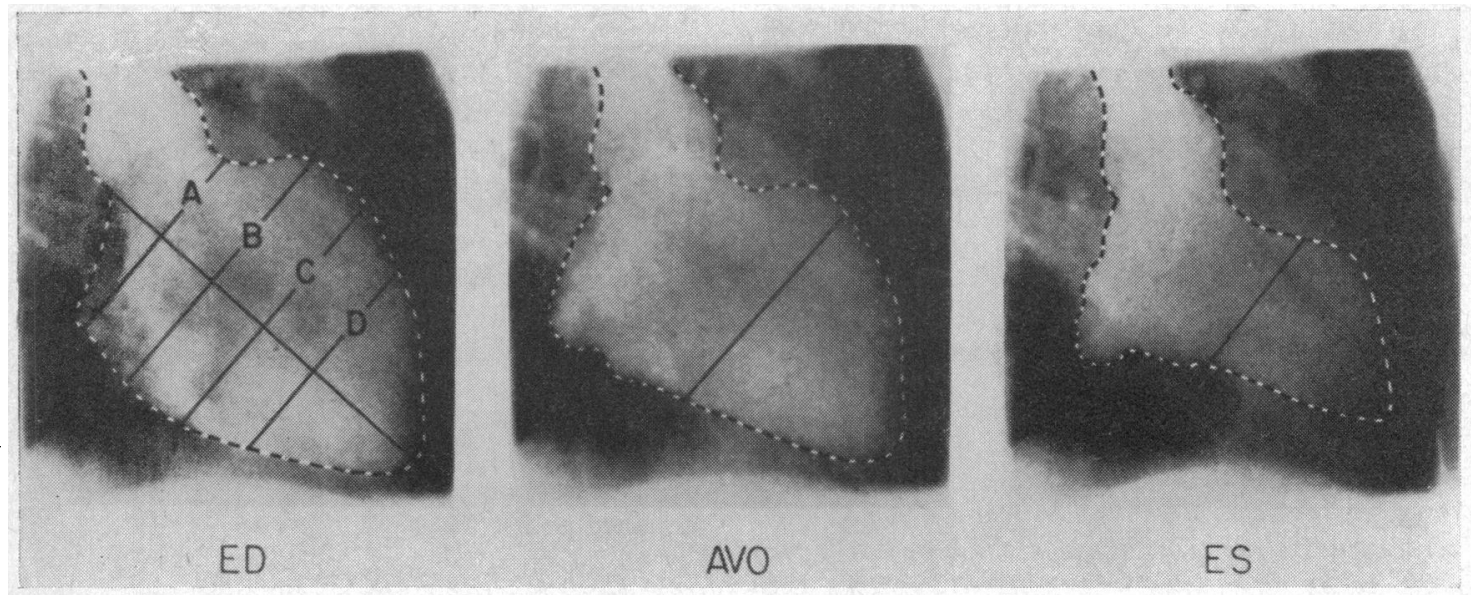

FIG. 5 Left ventricular cineangiogram from a patient with mitral valve prolapse. Chords $A$ to $D$ are identified in the end-diastolic $(E D)$ frame. Significant mitral valve prolapse and fibre shortening occurred before aortic valve opening ( $A V O)$. ES =end-systole.

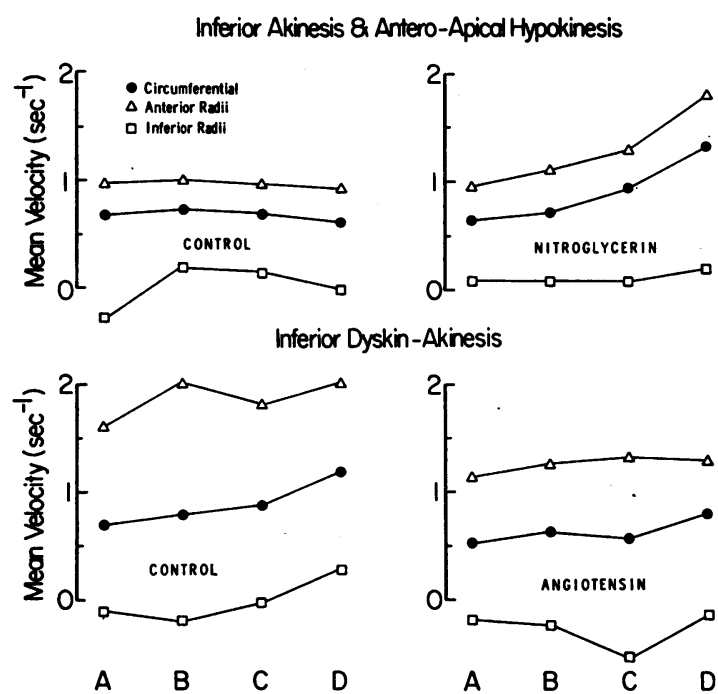

FIG. 6 Effects of nitroglycerin (top) and angiotensin infusion (bottom) on mean $V_{\mathrm{CF}}$ and normalized hemichord (radii) velocity in 2 patients with asynergy. Nitroglycerin resulted in improvement of the anteroapical hypokinesis with little change in the inferior akinesis. In contrast, angiotensin produced a reduction in the velocity of the anterior wall; paradoxical motion developed in inferior hemichords $C$ and $D$. Dyskin $=$ dyskinesis.

viously reported by Karliner and associates (I97Ib). Similarly, we observed a small amount of fibre shortening before aortic valve opening associated with a slight $(3 \%)$ reduction in left ventricular volume; these dimensional changes have been explained on the basis of redistribution of left ventricular volume towards the mitral valve area (Karliner, Bouchard, and Gault, 1971a).

Mean and 'instantaneous' $V_{C F}$ were depressed in the areas of myocardium involved by abnormalities of contraction; however, when asynergy involved only one of two opposing walls, measurements of the velocity at the hemichords (or radii) provided a better definition of regional performance (Fig. 3 and 6). $V_{C F}$ was normal at the basal chords (A and B) in the patients with apical asynergy. Of interest is one patient with apical hypokinesis who showed increased mean as well as max $V_{C F}$ at chord $B$. This augmented contraction of the non-involved area has also been observed by others (Klein, Herman, and Gorlin, 1967; Hood, 1970). Though the reason for this localized increase in the velocity of shortening is not clear, several explanations may be postulated: hypertrophy of the non-involved myocardium (Bergmann, 1968), a rise in circulating catecholamines (Richardson, Woods, and Bagwell, 1960), or local metabolic readjustments (Gudbjarnason and Puri, 1969). In addition, it has been suggested that two determinants of end-diastolic myocardial fibre stretch are end-diastolic stress and end-diastolic compliance (Gaasch et al., 1972). In this patient end-diastolic stress was increased (LVEDP $=18 \mathrm{mmHg}$ ). If compliance was normal in the non-ischaemic myocardium, end-diastolic muscle fibre stretch in this area may have been increased leading to augmented muscle function secondary to the Starling mechanism.

In one patient with asynergy, angiotensin (in- 
creased afterload) produced a generalized reduction in the velocity and the extent of shortening of the non-akinetic myocardium, while in a second similar patient, nitroglycerin was associated with the opposite effect. Covell and associates (1973) have made similar observations in dogs suggesting that $\mathrm{V}_{\mathrm{CF}}$ is sensitive to acute changes in afterload. Though a reduction in both afterload and preload occurs with nitroglycerin (Dumesnil et al., 1973; Burggraf and Parker, 1974), other mechanisms, such as improvement in myocardial oxygen demandsupply relation, may be responsible for the observed changes. Pine and associates (1973) have observed improvement in wall motion after aortocoronary bypass surgery only in those asynergic areas that showed improvement with nitroglycerin during the preoperative evaluation. These findings suggest that some asynergic areas contain viable myocardium which is capable of improving its performance when loading conditions or oxygen demand-supply relations are altered.

It has been suggested that impaired left ventricular performance in rheumatic mitral stenosis results from a localized abnormality involving the posterobasal area of the left ventricle (Heller and Carleton, 1970). A reduction of mean and $\max V_{C F}$ confined to the base was seen in a patient with mitral stenosis who had a normal ejection fraction and a normal $\mathrm{V}_{\mathrm{CF}}$ at the other chords. However, more generalized abnormalities of contraction have also been reported in patients with mitral stenosis (Holzer et al., 1973). The aetiology of these abnormalities is not clear though residual effects of rheumatic myocarditis (Holzer et al., 1973) as well as immobilization and atrophy of the posterobasal wall secondary to thickening of the valve leaflets and chordae tendineae (Grant, I953; Heller and Carleton, 1970) have been suggested.

Angiocardiographic descriptions of the prolapsing mitral valve syndrome have focused primarily on the abnormalities of the mitral valve apparatus. However, additional information has indicated that the disorder is not limited to the mitral valve. Recent reports have described abnormalities of left ventricular contraction; Liedtke et al. (1973) found reduced mean $V_{C F}$ at a basal chord in 9 patients with systolic click syndrome, two of whom had prolapse of the mitral valve shown angiographically. Scampardonis and associates (1973) have described 5 different patterns of left ventricular contraction, including a hyperdynamic, cavity obliteration type, but no segmental analysis of contraction was reported by them. In addition to a reduced mean $\mathrm{V}_{\mathrm{CF}}$ at the basal chord, our patient with mitral valve prolapse demonstrated a significant reduction $(22 \%)$ in the left ventricular volume before aortic valve opening accompanied by an early peak in $\mathrm{V}_{\mathrm{CF}}$ (Fig. 4 and 5). In this patient the early prolapse led to a partial translocation of ventricular volume into the posteriorly displaced leaflets. These changes in volume and $V_{C F}$ before aortic valve opening were more dramatic than those observed in the patient with chronic mitral insufficiency. The absence of a true isovolumic period in this type of patient may limit the use of isovolumic indices of contractility. The patient with chronic mitral insufficiency demonstrated uniform velocity of fibre shortening in all chords; though mean $V_{C F}$ and systolic ejection fraction were normal, $\max V_{C F}$ was slightly reduced (Fig. 4). Eckberg and associates (1973) have recently reported a group of patients with chronic severe mitral insufficiency, normal systolic ejection, and reduced $\mathrm{V}_{\mathrm{CF}}$. They have postulated that the rapid unloading occurring in these patients, caused by regurgitation before aortic valve opening, may help to maintain a normal ejection fraction in the presence of a reduced inotropic state. Though a good correlation between mean $V_{C F}$ and $\max V_{C F}$ has been reported, occasional instances of discrepancy between the two measurements have been observed (Karliner et al., 197rb).

The determination of $\mathrm{V}_{\mathrm{CF}}$ at multiple chords, complemented when necessary by measurements of the velocity at the various hemichords, appears to be of value as a quantitative approach to the evaluation of disorders of regional contraction. Comparison among patients is possible since the velocity measurements are normalized. Potential uses of this technique include follow-up of patients with coronary artery disease, particularly those subjected to some therapeutic intervention. The sensitivity of $\mathrm{V}_{\mathrm{CF}}$ to acute changes in afterload, however, may limit in some instances the usefulness of this measurement in quantitating segmental contractility.

The authors wish to thank Doctors James K. Alexander and Robert Hall for their encouragement and critical comments.

\section{References}

Bergmann, V. W. (1968). Der Bindegewebsgehalt im Herzmuskel des Menschen bei akutem und chronischem Myokardinfarkt. Archiv für Kreislaufforschung, 56, 106.

Burggraf, G. W., and Parker, J. O. (1974). Left ventricular volume changes after amyl nitrite and nitroglycerin in man as measured by ultrasound. Circulation, 49, 136.

Covell, J. W., Mahler, F., O'Rourke, R., and Ross, J., Jr. (1973). Velocity of left ventricular fibre shortening during acute loading and altered contractility in the conscious dog (abstract). Circulation, 48, Suppl. IV, 66. 
Dumesnil, J. G., Ritman, E. L., Frye, R. L., Davis, G. D., Gau, G. T., Sturm, R. E., and Wood, E. H. (I973). Regional left ventricular wall dynamics before and after the administration of oral nitroglycerine (abstract). Circulation, 48, Suppl. IV, ro4.

Eckberg, D. L., Gault, J. H., Bouchard, R. L., Karliner, J. S., and Ross, J., Jr. (I973). Mechanics of left ventricular contraction in chronic severe mitral regurgitation. Circulation, 47, 1252.

Gaasch, W. H., Battle, W. E., Oboler, A. A., Banas, J. S., and Levine, H. J. (1972). Left ventricular stress and compliance in man: with special reference to normalized ventricular function curves. Circulation, 45, 746.

Gault, J. H., Ross, J., Jr., and Braunwald, E. (I968). Contractile state of the left ventricle in man. Instantaneous tension-velocity-length relations in patients with and without disease of the left ventricular myocardium. Circulation Research, 22, $45 \mathrm{I}$.

Grant, R. P. (1953). Architectonics of the heart. American Heart fournal, 46, 405.

Greene, D. G., Carlisle, R., Grant, C., and Bunnell, I. L. (1967). Estimations of left ventricular volume by oneplane cineangiography. Circulation, 35, 6r.

Gudbjarnason, S., and Puri, P. S. (1969). Adenine-nucleotide levels of nonischemic cardiac muscle following cardiac coronary occlusion. Federation Proceedings, 28, 452.

Heller, S. J., and Carleton, R. A. (1970). Abnormal left ventricular contraction in patients with mitral stenosis. Circulation, 42, 1099.

Holzer, J. A., Karliner, J. S., O'Rourke, R. A., and Peterson, K. L. (1973). Quantitative angiographic analysis of the left ventricle in patients with isolated rheumatic mitral stenosis. British Heart fournal, 35, 497.

Hood, W. B. (1970). Experimental myocardial infarction. III. Recovery of left ventricular function in the healing phase. Contribution of increase fiber shortening in noninfarcted myocardium. American Heart fournal, 79, 531 . Karliner, J. S., Bouchard, R. J., and Gault, J. H. (I97Ia). Dimensional changes of the human left ventricle prior to aortic valve opening. A cineangiographic study in patients with and without left heart disease. Circulation, 44, 312.

Karliner, J. S., Gault, J. H. Eckberg, D., Mullins, C. B., and Ross, J., Jr. (197rb). Mean velocity of fiber shortening. A simplified measure of left ventricular myocardial contractility. Circulation, 44, 323.

Klein, M. D., Herman, M. V., and Gorlin, R. (1967). A hemodynamic study of left ventricular aneurysm. Circulation, 35, 6r4.

Liedtke, A. J., Gault, J. H., Leaman, D. M., and Blumenthal, M. S. (I973). Geometry of left ventricular contraction in the systolic click syndrome: characterization of a segmental myocardial abnormality. Circulation, 47, 27.

Pine, R., Meister, S. G., Banka, V. S., Feldman, M. S., Trout, R., and Helfant, R. H. (1973). Detection of reversible ventricular contraction abnormalities with nitroglycerin: correlation with post-coronary bypass ventriculography (abstract). Circulation, 48, Suppl. IV, I04.

Richardson, J. A., Woods, E. F., and Bagwell, E. E. (1960). Circulating epinephrine and norepinephrine in coronary occlusion. American fournal of Cardiology, 5, 6r3.

Sandler, H., and Dodge, H. T. (1963). Left ventricular tension and stress in man. Circulation Research, 13, 91.

Scampardonis, G., Yang, S. S., Maranhao, V., Goldberg, H., and Gooch, A. S. (1973). Left ventricular abnormalities in prolapsed mitral leaflet syndrome. Review of eightyseven cases. Circulation, 48, 287.

Requests for reprints to Dr. William H. Gaasch, New England Medical Center Hospitals, I7I Harrison Avenue, Boston, Mass. O2I I I, U.S.A. 